\title{
Performing women: The gendered dimensions of the UK new research economy
}

By

Catherine Fletcher (University of the West of England) Rebecca Boden (University of Wales Institute, Cardiff) Julie Kent (University of the West of England) Julie Tinson (University of Stirling)

Contact details:

e-mail: Cath_Fletcher@btinternet.com

Department of Humanities, Languages and Social Sciences

University of the West of England

Coldharbour Lane

Bristol BS16 1QY 


\title{
Performing women: the gendered dimensions of the UK new research economy
}

\begin{abstract}
This paper explores the development and maintenance of familiar gendered employment patterns and practices in UK universities, which are exemplars of new modes of knowledge production, commodification and marketisation. After discussing in detail the evidence of gender discrimination in UK higher education and the changes in the academic labour process consequent to the incorporation, at least at the policy level, of universities into the 'knowledge economy', institution-specific data is used to highlight the gendered aspects of the research economy from the three intermeshing perspectives of research culture, research capital and the research production process. This nexus is constructed in such a way as to systematically militate against women's full and equal involvement in research. Lack of transparency, increased competition and lower levels of collegiate activity coupled with networking based on homosociability are contributing to a research production process where women are marginalized.
\end{abstract}

Key words

Gender equity, universities, research culture, research capital, research production process 


\section{Performing women: the gendered dimensions of the UK new research economy}

\section{Introduction}

So-called 'knowledge economies' ${ }^{1}$ imply the commodification of knowledge, an emphasis on productive capacity with regard to knowledge and its control as an asset in order to yield value to its owners. The intellectual nature of the commodity makes control of labour in knowledge economies a key determinant of 'profitability'. Consequently, the efficient capture, control and exploitation of the surplus value of workers' labour is of central importance. Indeed, in sectors such as the science-based industries, changes in scientists' traditional, professional employment patterns and conditions consequent upon the commodification of knowledge are readily apparent (Boden, Cox, Nedeva and Barker 2004).

Given these developments, it might be anticipated that familiar aspects of the labour process such as surveillance, discipline, the instigation of self-discipline, regulation and the development of labour stratification through discrimination between different classes of workers (for instance, along gendered or racialised lines) might be replicated in the new knowledge economies. This paper conceptualises British universities as 'knowledge economy' organisations and explores how these aspects of the labour process produce gendered outcomes despite the existence of organisational policy initiatives that seek the opposite effect.

University research is often characterised as being of central importance to a healthy UK knowledge economy. Government policy emphasises that universities exist to generate new knowledge through research and to train new workers/citizens for a knowledge-based economy/society (Department of Education and Skills 2003). Such policies are given real teeth by the fact that UK universities receive the overwhelming majority of their funding from the public sector, which for the past 25 years has been marked by new public management discourses that emphasise the commodification and marketisation of public sector goods, services and knowledge.

The embedding of universities into such a 'research knowledge economy' has resulted in knowledge production within the academy being increasingly

\footnotetext{
${ }^{1}$ We recognise that the term 'knowledge economy' is problematic, but it is outside the constraints of this paper to explore this here.
} 
commodified, managed and subject to audit. The potentially high value of intellectual labour to knowledge economy organisations has resulted in an emphasis on the quality and quantity of individual and small team research performativity. Value is generally measured and evaluated in terms of economic utility. Management control tools, such as the national Research Assessment Exercise $^{2}$, seek to ensure the regular, auditable production of 'quality-assured' knowledge, with individuals held to account within their institutions for the volume of what they have produced and its perceived quality.

As is usual with labour processes, this has a gendered dimension. Research evidence convincingly demonstrates the existence of a very substantial gendered divide within higher education. For instance, women enjoy less enhanced career prospects and are consistently paid substantially less than their male counterparts (Halvorsen 2002). But whilst the existence of an academic labour market stratified by gender is well evidenced and widely acknowledged (see, for example, Knights and Richards 2003), little is known about how such processes and practices are actualised at an organisational level. This is the principal focus of this paper. Consequently, we explore women's engagement in this new research economy by utilising data collected during a single institutional study conducted at an English university that we have called 'Shires'. It should be noted that there are some differences in the structure and funding of higher education between the UK's constituent elements. However, these pertain principally to issues such as separate funding councils and, in the case of Wales and Scotland, some regional control over higher education policy. We do not believe that these are differences that make a significant difference with regard to gender issues, but the existing literature on this topic does not, for the most part, differentiate between the constituent elements of the UK. Moreover, Welsh and Scottish devolution may be so new that any effects of these more local controls have yet to work their way through. For these reasons, we refer to the ' $U K$ ' rather than to 'England' more specifically when discussing the general environmental context.

This paper draws upon, but does not exhaustively utilise, data from our yearlong study. In this study we interviewed 60 women academics at all grading levels from casual hourly paid lecturers to professors. A small minority were solely researchers, the majority were teacher-researchers, and another small

\footnotetext{
${ }^{2}$ The Research Assessment Exercise is a reasonably regular national peer review and assessment of research 'quality'. The exercise is undertaken by the UK university funding councils. The results determine, via a formula, the distribution of a large part of funding council research expenditure. For more information see: www.rae.ac.uk or Lucas 2004.
} 
minority were employed on teaching-only contracts. They were selected through a stratified sampling frame and were evenly distributed across the faculties of Shires, which embody every major discipline area with the exception of the natural sciences, and across grades and job roles. Shires has a bias towards applied subjects such as law and the health professions (but does not train doctors). Nevertheless, our sampling was not designed to be statistically representative. We also interviewed 22 key men and women occupying university-designated 'research manager' roles who are also academics. Again, these were selected to ensure an even distribution across all faculties. One respondent, who coterminously occupied all of the senior research management roles within one faculty, withdrew cooperation without explanation. This therefore represents an, albeit minor, limitation to the coverage achieved by these interviews. Interviews were recorded, transcribed and thematically analysed by close textual reading undertaken by all of the researchers. NVivo was used to facilitate this exercise. Additionally, we administered a questionnaire to all +/1400 male and female academics in the university (the personnel department was unable to give us a more accurate figure). This produced 275 usable replies (approximately a 20\% response rate). The questionnaire, analysed using SPSS, captured important base-line demographic data and further contributed to our understandings derived from the qualitative interview data of feelings and experiences around research activity by providing important contextual detail. However, the primary focus of this study was qualitative rather than quantitative. Additionally, we had access to some anonymised personnel data and the policy documents of Shires.

This paper is organised into five further sections. In the section two we detail the evidence of gender discrimination in UK higher education and the changes in the academic labour process consequent to the incorporation, at least at the policy level, of universities into the 'knowledge economy'. In sections 3, 4, and 5 we analyse the gendered aspects of the research economy at Shires from the three intermeshing perspectives of research culture, research capital and the research production process respectively. This is followed by some conclusions.

\section{The academic labour process}

For the past 25 years, UK government policy has been increasingly transformed by neo-liberal ideologies (Dean 1999; Rose 1999) Consequently, policies have asserted the role of the public sphere in supporting and sustaining the development of private business through public-private partnerships (Giddens 1998). A key policy has been the stimulation of a market economy which increasingly relies on the intensive application of sophisticated (in Western 
terms) knowledge in response to accelerating globalised competition. In turn, higher education policy has emphasised the role of universities in producing both qualified workers and economically useful/exploitable research-based knowledge products to contribute to such an economy (Shore and Wright 1999).

Such a redefined role has combined with new public management (NPM) discourses to produce a marked shift in the relationship between government and universities. Universities, through NPM technologies such as performance audit, contractual funding (instead of block grants) and target setting, have been increasingly tightly drawn under government control (Strathern 2000). A plethora of government or government-inspired regulatory/audit schemes have been spawned, including Subject Performance Review, Subject Benchmarking, Institutional Review, the Research Assessment Exercise and Transparent Approach to Costing (TRAC).

Although these changes originate in government, Henkel (2000) found that they have been enthusiastically embraced by new management elites in universities as useful tools to ensure staff performance. Largely through these mechanisms, policy has worked its way through into the daily lives of academics as management elites have sought to achieve hegemony over academics and their work. Performativity demands, in both teaching and research, are characterised by high levels of control, performance audit, measurement, and target setting, which stand in stark contrast to pre-existing regimes of professional autonomy ((Brooks and Mackinnon 2001; Currie, Harris and Theale 2000; Henkel 2000; Strathern 2000). The management techniques and practices that are a consequence of neo-liberal knowledge economy policies therefore collectively determine not just the national criteria for higher education institutional policies and funding but also the personal performativity demands to which individual academics are subject (Howie and Tauchert 2002).

There is convincing evidence that, in the UK at least, these new labour regimes are highly gendered, seriously disadvantaging women academics in areas such as contracts, conditions, promotions and pay (Clark, Chandler and Barry 1999; Forster 2000; Malik and Styver Lie 1994; West and Lyon 1995). Across all parts of the sector, nearly half of women academics are on the lowest lecturer scale and only $24 \%$ have been promoted to Senior Lecturer (called Principal Lecturer in newer universities) (THES, 21 March 2003). Halvorsen (2002) estimated that, at the current rate of change, it will be 68 years before half of readers and professors are women. Moreover, in the highly casualised UK HE sector women are twice as likely as men to be employed on fixed-term contracts (Swain 1998). The pay 
gap between men and women academics is well documented (Association of University Teachers 2004; Bett Report 1999). Other research has addressed the gender dimensions of specific issues such as research grant applications (Bagilhole 2002), research selectivity (Harley 2001), and what action might be taken to ameliorate problems of inequity (Husu 2001; Morley 1996).

'New' universities (those created from polytechnics and colleges as part of the massification of UK HE since 1992) such as Shires, employ more women and are more likely to promote them than older institutions. But the difference is slight. For instance, about $16 \%$ of professors in post-1992 universities are women compared to the national average of $13.1 \%$.

The Dearing report (1997), commissioned by the government as an inquiry into the state of higher education, found much of concern regarding staff pay and conditions. In response to Dearing, the employers established the Bett committee to undertake an independent review of staff terms and conditions in higher education. This committee's report (Bett report 1999) highlighted the severity of the problems

It is inevitable that further significant increases in the proportions of women in higher level posts will take several years to achieve. However, we believe there is a considerable onus on HE institutions to make progress as rapidly as recruitment and promotion on merit will allow. To this end we recommend that each university and HE college should have, and publish, a clear statement of its policies on equal opportunities and of the steps it is taking to ensure equality for women. Such activities should included family-friendly employment practices, developmental training so that more women are ready to pass through present glass ceilings, and clear mechanisms and criteria for promotions. (Bett Report 1999 paragraph 329)

In response to such urgings, in 2003 the Higher Education Funding Council for England (the body through which government funds for English HE are distributed) set up an 18 month research programme to investigate equal opportunities issues (HEFCE 2005). It also commissioned an 'Equality Proofing of Research Assessment' report from the Equality Challenge Unit of the government's Department of Trade and Industry (RAE 2003). Both reports found cause for concern.

We argue that whilst such gender audits and exercises demonstrate that women are severely institutionally disadvantaged and there are calls for increased 
transparency to attenuate discrimination, there may be a disjuncture between the overt commitments to equality of opportunity and other, knowledge economy related, mechanisms put in place to govern the lives of academics, determine their performativity and shape their professional identities. We argue that this is not principally the product of direct sexism. Rather, managerialist practices in the modernised universities may produce gendered outcomes if the processes of performance measurement, management regimes and new institutional cultures embody some gender bias. That is, the principal cause of women's unequal treatment is institutionalised sexism. Speaking graphically, Morley (2003) describes all quality audit procedures as being

a one-way gaze, reminiscent of pornographic representation. The continuous improvement discourse is reminiscent of the cultural pressures on women in general to strive for perfection...It also echoes another regulatory force, that is original sin. Women enter the academy as flawed and imperfect academics and they have to struggle to redeem themselves (page 157)

Fenton (2003) summarises previous research in this area as pointing to two key problems. First, academic environments promote homosociability, binding men into a hierarchical fraternity that marginalises women. Second, competitive values are being reinforced by changes in higher education that tie the production of academic work to market forces and ensure a more overt split between research and teaching than ever before. One of the findings of one of the projects in the HEFCE study described above was that that 'greater parity between research and teaching' could be a factor in improving equal opportunities in universities (HEFCE 2005). For Morley (2003), the culture of measurement reinforces 'macho' competition while micropolitical relays of gendered power are notoriously difficult to capture, with the same people who operate distorted practices in relation to sponsorship and distribution of resources and opportunities being charged with maintaining transparency elsewhere in the academy.

The 2003 white paper, The Future of Higher Education, will arguably do little to address these deeply embedded gender distortions. It seeks to preserve the divide between high status research and low status teaching and therefore potentially reinforces competitive values and the micropolitics of gendered power to which Morley refers. For instance, it offers no resources to address inequality but instead gives responsibility to institutions to deal with the problems - something that Fenton (2003) sees as problematic, since rooting out of discrimination requires government commitment and legal action. The white 
paper's recommendations are likely to reinforce current patterns since the proposed increasing selectivity in research funding will reward people already highly prized with special deals. Any increase in the funding gap between elite and non-elite universities will negatively impact on female staff in new universities who will be doubly disadvantaged.

The academic literature and policy documents point to the presence of a substantial and complex set of problems with regard to gender in higher education. The failure to make progress on these issues and their persistence in the face of continued pronouncements also indicates that this is far from a 'pipeline' problem that will be resolved as women 'join the procession' (Morley 2003:154). Rather, the nature, functioning, structure and ethos of higher education in the UK appears to militate against gender equity. Within this frame, individual research performance is of special importance because of the importance attached to research in the development of knowledge economies. Hence, the gendered nature of research performance may provide important understandings of the gendered nature of UK higher education and vice versa.

Notions of 'research productivity' can be seen as embodying hidden agendas, with research on or by women and even certain methodologies such as qualitative research in which women tend to predominate being perceived as being outside the 'mainstream' (Knights and Richards 2003; Wyn, Acker and Richards 2000).

The Research Assessment Exercise in particular has been the subject of much criticism with regard to gender. The Equality Challenge Unit of the DTI in its report on 'Equality Proofing of Research Assessment' concluded, for instance, that:

The Research Assessment Exercise was premised on peer review which is conducted through panel appraisal. The panels for each Unit of Assessment (UoA) were selected through a process that has appeared to be less than transparent. The process has yielded, at the very least, a gender imbalance. The ethnic mix of the panels and proportion of disabled people on them is not known. Even allowing for the paucity of women in some subject areas, it is noteworthy that they made up only about one fifth of ordinary panel membership in the 2001 exercise and one sixth of Chairs. (RAE 2003: paragraph 34)

For Harding the very 'idea that fair and objective judgements can be made and rewards solely allocated in proportion to worth, to individual merit, is at best 
naïve, and at worst, a deception' (2002: 285). She criticises the RAE as a playing field that is already biased, as candidates with the most publications win when all that is really necessary is evidence of some appropriate level of productivity.

The nature of universities' research cultures and the management of research work are becoming ever more crucial sites for investigation into gender equity as women's subordinate positions are exacerbated by the increasing importance attached to individual research performativity by employers as a mechanism for regulating career enhancement. The highly managerialist and performative culture that has developed has simultaneously made research an important site of competitive individual behaviour and a deeply gendered practice.

Whilst the macro-level story is well-documented and researched (e.g Knights and Richards 2003), understanding of how this gendered outcome is achieved at the micro level is limited. To do this, we now turn to our single-institution case study. We have considered academic engagement with research activity in three domains: culture, capital and processes. Finally, we address how these three domains intersect at an organisational level to produce gendered outcomes.

\section{Research cultures}

Research work in universities is characterised by enduring and heterogeneous relationships, practices and meanings, embodied by those who work in the academy. We refer to such characteristics as 'research culture'. Following Bourdieu (1988), the notion of habitus or cultural practice (Swartz 1997) is useful here. That is, research culture can be usefully understood as the daily cultural and social practice of individuals - the way individuals do researcher. It follows that research culture can be neither monolithic nor exclusively determined by managerial policy mechanisms. Resistance is also always possible. Such a conceptualisation leads to consideration of how individuals might engage with and construct their identity with regard to such cultures and how they shape expectations and behaviours.

The new universities had always been management-led institutions under external direction and control. Until their reinvention as universities in the early 1990s, their prime activity was teaching. But, by then universities were increasingly being drawn into a central role in sustaining the knowledge economy through both teaching and research. What research there was in new universities was typically marginal, small-scale, applied and for local 'clients'. 
For the most part, the new universities were not vested in the particular longstanding traditional research cultures of their older counterparts.

The assumption of university status by these institutions therefore created an externally-generated strategic imperative to develop research and the nature of the institutions determined that such a shift would be management-led. For many, including Shires, the development of research therefore became a strategic management priority undertaken in direct response to external neo-liberal knowledge economy policy imperatives, given impetus by funding mechanisms and regulatory regimes of control.

Management-led strategic initiatives tend to be heavily reliant on performance measurement and management, audit and regulation to their achieve goals. Such performativity demands may shape the nature of research cultures as the activity is determined by the necessity of achieving results measured in terms of, for instance, league tables or financial rewards. Morley asserts that academics are being asked to 'reinvent themselves, their courses, their cultural capital and their research as marketable commodities' (2003:68). Research becomes a competitive and outcome oriented practice. In the rest of this section we explore the extent to which the development of such a research culture at Shires was gendered.

Shires sought to re-brand itself as research focussed as well as teaching led often in its efforts to attract good research staff to come and work there in order to stimulate the research environment. Internally it promulgated new academic staff profiles emphasising that all academics should teach and undertake research and/or advanced consultancy work, and the importance of attracting external research funding. Such policies provided the basis for an early retirement/voluntary severance programme that allowed 'teaching only' staff to leave the institution, in some cases with handsome payoffs. They were, in turn, replaced with new staff deemed to be more active in research (and, in many instances, lower down the salary scales). In most faculties time for research was tightly controlled and given as a remission for teaching and only in return for research performance deemed acceptable by managers.

The management elite of Shires thus sought to create a research culture that was performance driven and responsive to the exogenous imperatives of the knowledge economy. The management emphasised research production and made it an integral part of the performance expectations to which staff were subjected. Allying oneself convincingly to such a culture and making use of it brought personal recognition, time for research and promotion. 
Some women felt uncomfortable with this performative and competitive culture:

It's hard to generalise, and not all women, but there is a slight tendency for the women to be more collegiate, or good corporate citizens, rather than self-absorbed, or just focused on their individual career paths. Things used to be more embedded in the context of teaching and research and in a more collegiate atmosphere. Whereas now, your performance and your promotion and so on is about doing single authored bits of work and the devil take the hindmost (Daisy, Senior Academic)

Some women felt that the management's policies were insulting and reflected a poor understanding of the nature of traditional academic work. They were extremely disparaging about what they saw as a very shallow, performance driven research culture that had developed over the last 15 years and had led to anxiety about research 'production':

It's a very good stick, it's a terribly poor carrot and as a discourse, it's shameful.... I think holding this up as a badge of honour to be aimed for is just laughable. (Rose, Senior Academic)

There was anger and disappointment in the accounts of younger academics recently recruited to boost the research profile of the university who had been led to expect a greater support for research than was the case. Overall, there was little or no evidence that any respondents thought that the new strategic policy emphasising research had led, or was likely to lead to a research culture where the activity was truly regarded as a core activity of all academics with all the consequent support mechanisms, rather than one that was additional to or an alternative to teaching. For most of our women respondents research remained something that was an 'additional' activity in the eyes of the university, personal (as opposed to contractual) to them and/or marginalised. This was then a culture, at least at an institutional level, that was, in many senses, alien to them with consequent denial of access to important resources, incentives and rewards.

Becher and Trowler (2001) describe universities as faction-riven agglomerations of academic tribes and for many of our respondents the culture in their own more local grouping was more important, and something that they often felt more comfortable speaking about. For some women, what determines whether an academic environment is conducive are the conditions at the micro level of 
the sub-organisation, department or discipline group rather than at the level of the institution (Packer 1995).

At this level, whilst some of our respondents had learned how to access and utilise research cultures, others had definitely not. There was recognition that pockets of what was perceived as excellence existed within some departments at Shires, but these were often in areas that women felt excluded from: especially in science, engineering and technology disciplines. Thus there was a sense of gendered hierarchy of disciplines, along the lines of polarity suggested by Bourdieu (1988). Some faculties were perceived as having a stronger and more inclusive research culture than others. In some departments, particularly where there were lower numbers of women in traditionally male subjects, there were accounts of alienation, macho management and overt and covert sexism which research managers appeared to be unaware of.

Many respondents mentioned the advantages and difficulties of networking and its importance in integrating oneself with research culture. Those women who were experienced and successful researchers were also good networkers. But many women said that they did not have the necessary contacts to be successful networkers. Women with heavy domestic responsibilities experienced particular difficulties. Some saw gaining access to external networks as problematic. Many referred to cronyism and 'old boy networks' and said that contracts out for tender had already been 'stitched up'.

I don't know, unless we have a radical change in the structure and the attitude of the research councils, which I can't see because it's an old boys' network. The people who sit on the [research] council, who make the decisions and review all the applications are the people who are either directly benefiting or have benefited in the past, or their cronies benefit from the money. I can't see how that's going to change. (Sheila, Senior Lecturer)

Sheila's comments above reflect a quite generally perceived problem of homosociability that reproduced the corps (Bourdieu 1988), where senior men were far more likely to include junior men in activities or overtly bestow patronage on them, thus further disadvantaging women in the absence of an equivalent network of senior women.

I think that's the difficulty for women and I also think there is this nonclubability, different clubability. I certainly think there is a bit of...yes, gossip in the sense of deciding things...contrasting it to my previous job, an awful lot of 
jockeying for your place was done in the pub afterwards. There was I with two children under five, I certainly wasn't hanging around to go to the pub. That was a conscious thing and some women did play that game but it shouldn't really have been done in that way. I suspect there still is that. (Liz, Senior Academic)

Mentoring was seen as an important part of gaining access to research circles, of recruitment into the research corps. Mentoring can be complex to define (Colley 2003) and here we take it to mean guidance/assistance from more experienced colleagues who can act as role models, critical friends and supporters and champions. Some women appeared to be especially supportive of their female less-experienced colleagues, even though they sometimes did this in a somewhat self-effacing way by, for instance, helping others to network and secure a publishing deal. In terms of informal organisation, women valued research mentorship and expressed a wish to see a greater degree of such assistance.

Some women who had successfully engaged with this research culture and benefited from it experienced resentment. For example, one early career researcher related how it had been suggested that she was sleeping her way to the top because of her close working relationship with another member of staff. A senior research manager had advised her that, despite the advantages of being mentored by her colleague, she ought to develop her work independently.

The dominant cultural practices at Shires were instituted by a management regime anxious to respond directly to exogenous knowledge economy imperatives. This culture was performance driven and heavily regulated. Women academics felt largely alienated from or were disparaging of such practices. Where they did attempt to participate, they often experienced difficulties in gaining access to the culture.

\section{Research capital}

A key characteristic of neo-liberal regimes is their emphasis on individualisation to the point of social atomisation (Rose 1994). Labour processes in such societies might be characterised as 'post-Fordist', not in the sense of a return to 'craft work', but rather a process of neo-liberal subjectification (Horak 2004). PostFordist labour conditions emphasise the obligation of individuals to equip themselves to be productive, flexible and adaptive, and to move seamlessly in the world of work as economic necessity demands. Post-Fordist academics, it has been argued, are 'atomised, expected to be "self-managed" and "self-reliant", to 
work in a flexible manner, and are encouraged to compete amongst themselves and between institutions.' (Boden and Epstein 2006).

It follows from this that the success of knowledge workers in knowledge economies will depend upon possessing a suitable stock of personal 'research capital', such as skills, training and resources, and the ability to deploy it effectively (Hatt, Kent and Britton 1999). In this section we explore the extent to which women's life courses and experiences at Shires might have affected their ability to access or accumulate sufficient amounts of appropriate research capital.

The women in our study became academics via diverse routes and this was reflected in their individual levels of research capital. Some had taken a quite traditional path by completing a $\mathrm{PhD}$ and/or then becoming contract researchers, followed by a lecturing post. Others were experienced professionals who had come to the university to teach professional or vocationally oriented courses. A third group of women had joined the university primarily or exclusively to teach rather than to undertake research and had little or no professional or research experience. Table 1 illustrates the possible difficulties that lecturing staff may face at entry in meeting the Shires requirement of being a teacher/researcher or a teacher/practitioner.

\section{INSERT TABLE 1 ABOUT HERE}

The diversity of women's entry routes at Shires has clear implications for their capital in terms of research awareness, skills and experience. Some women had entered higher education largely because of the supposed 'flexibility' (in a non post-Fordist sense) of academic work. In particular, a number of women respondents who entered via the professional or teaching routes did so because of a perception that family responsibilities could be more successfully managed doing this sort of work. This study did not seek explicitly to compare men and women but these are, we would argue, more likely to be considerations that affect women than men (especially historically). If women do indeed have a greater propensity than men do to enter academic work through the professional or teaching routes then they may be more likely to have a deficit of research awareness and skills compared with their male colleagues.

This diminished capital adversely affected women's habitus. For instance, many women experienced anxiety about the University's new strategy promoting 
engagement in research because of their lower levels of research capital and their primary affiliation as teachers.

I think it's very hard for those people who are teachers. I think it's very unfair in a way because there are people who have been here for 20 years and they came in as teachers and that's what they are and you can't expect people like that to suddenly be writing. It's scary enough trying to write when that's what you are supposed to be doing, never mind if I had been teaching for 20 years. You are just making people in fear of their jobs and I think that's very unfair. (Ruby, Senior academic)

Lack of confidence was a particular issue for those whose routes into academia have been through professional or teaching routes. Many women spoke of their difficulties in becoming more competitive and 'blowing their own trumpet'. This included women in senior research management positions who spoke of aspects of working in management as being unsatisfying when they conflicted with their core values, and who had made strategic decisions not to seek further promotion.

Research cultures could conceivably play a major part in overcoming these capital deficiencies, for instance by providing mentoring support or an inclusive and supportive environment. Unfortunately, as explained above, women at Shires felt that the culture was deficient in this regard. Davies and Holloway (1995) stress that, in the managerial culture of universities, rigid definitions of active and inactive researchers disadvantage women by making it hard to shift between the two. There appeared few ways in which women at Shires could overcome their research capital deficiencies when these arose. Indeed, in some faculties, explicit management practices exacerbated the problem. In the business school, for instance, time for research was an explicit reward for doing research and was not accessible until a research track record had been established by the individual. Thus, the individual had to make a considerable self-investment in becoming 'research active' - to acquire sufficient capital - before they were permitted to join the 'club' of researchers rewarded with time and other resources

Active participation by individuals in research activities in the University required research capital. Acquiring such skills and knowledge was problematic for many women at Shires, often because of their entry routes. Generally, it was felt that the University did little to assist women with such capital accumulation. From a management point of view this is irrational behaviour, as failing to equip women with the resources they need to undertake research effectively meant, ultimately, that the University was less productive. We were unable to 
determine whether such problems were the result of overt discrimination or a simple failure to appreciate the problems that women faced in this regard. What did result was a particular and notable subjectification of women as those who were primarily teachers or responsible for pastoral care, whilst men were more likely to be in possession of sufficient research capital to become effective entrepreneurial workers in the internal research economy.

\section{Research Production Process}

The notion of the knowledge economy depends upon the incorporation of knowledge production and exploitation within some production process. Thus, in marketised and corporatised universities, research culture(s) and individual workers' research capital are brought together in a managed production process in which academic labour transforms resources (such as time, equipment or research grants) into income-generating knowledge commodities. The commodities produced are research tangibles (such as publications) that satisfy the demands of 'paying customers' (either government or private industry). Shires took such a managerialist approach: achieving an enhanced research profile was part of a market repositioning strategy.

Rationally, research is premium work for academics as, in contemporary universities, it tends to offer better promotion and reward prospects than teaching does. Many academics also find it brings the most psychic enjoyment. Shires restricted the time formally allocated to research work and access to it using a time/money accounting mechanism. Managers frequently argued that they should allocate staff time in proportion to the particular income stream (teaching fees, research contracts etc) attached to each activity. Shires' relatively low research income meant, it was often asserted, that it was not possible to allocate a lot of time to research and also that teaching income subsidised research activities. These arguments were rarely countered by reasoning that any cross-subsidisation of research might bring benefits for teaching and an enhanced institutional profile.

This system sent mixed messages. Research activity was a key part of the rebranding initiative and a major determinant of appointment and promotion prospects, demoting teaching to a comparatively low status. Yet, simultaneously, the institution deployed financial arguments to stress how important teaching was. This allowed the University to make research time an (allegedly) expensive reward for (essentially subjectively measured) previous success in research and 
for which staff, in many instances, competed with each other on an annual basis. This system was gendered, for reasons we now explore.

Such was the shortage of research time at Shires that competition for it was brisk. As with most academics nationally, staff often worked on their research outside of normal contracted hours, at weekends or in the evenings. They did this in order to produce enough outputs to compete effectively with their colleagues for research time. Thus they can be seen as neo-liberal subjects, anxious to improve themselves to gain success in the marketplace. This also had the effect of increasing the expected output from any given unit of research time, a process of work intensification that helped create a long-hours culture amongst research active staff. One woman expressed her frustrations thus

The main issue is just time. Time and the fact that to do a really, really good piece of work takes a long time. I think you could be talking a year or more before the paper comes to fruition. From what I was saying, there is this distortion about the fact that you have to get something out quickly. It's something that I am trying to address for me personally at the moment. I have to do enough quick and dirty papers to make sure that I don't lose my research hours that I have to bid for on an annual basis. But, on the other hand, there's a bit of me that just wants to do the stunningly good paper with all the bits, research design excellent and everything else excellent. (Emma, Senior Academic)

Such conditions are gendered because working 'all hours' has differential social implications for women and men (Currie, Harris and Theale 2000). Women often have greater domestic responsibilities and may not be able to or want to adopt 'masculinised' work patterns. Many women at Shires expressed the view that family responsibilities interfered with their ability to pursue their careers to a greater extent than they did for men.

Fenton (1999) argues that the split between high status research and low status teaching is a further disadvantage for women, who, despite nominally equal formal time allocations, often devote more actual time to administrative duties and pastoral care than men do. The competing demands between teaching, administration and research on staff time were seen as stressful by many at Shires, who found maintaining high standards in both teaching and research with limited resources highly problematic.

Some of my colleagues are doing 16 hours teaching a week -- they can't really be expected to be excellent researchers as well. I think it's a bit naïve...to be expected to be research active and teach and be excellent at everything. ... In terms of the 
white paper, it's a ridiculous policy anyway, because we are not going to be able to be great researchers and great teachers because we're not going to be funded that way. (Helen, Lecturer)

Some felt that women were often inclined to participate in activities in a more altruistic way and were better corporate citizens than male colleagues. This might work to their disadvantage in situations where increased competition for time and funding resources for research often led to single-mindedness to the point of ruthlessness. As Fenton (1999) argues, the industrialisation of higher education has led to a work environment that favours masculinised behaviour that is competitive, individualistic and often confrontational - something most of our women respondents at Shires felt uncomfortable with.

There needs to be some recognition of the value of collegiate activity,... a lot of it is tied up with what signals people get in terms of promotion strategy. The messages there are hugely mixed and so I think some clarity over that would help a lot. If the research allocation mechanisms weren't quite so short term: every year you have to prove your worth (Heidi, Senior academic)

If resources such as time were important determinants to shaping the gendered nature of research production processes, so too was gendered access/inclusion in the social aspects of the research process itself. Many women spoke of feeling excluded from research activities. For some, there was a monolithic male culture within their faculty, which led to men preferring to interact with other men. One young female academic referred to the newly arrived young males of her age as the 'suits' who were skilled at networking with established males and good at diplomacy. Many women felt marginalised by, for instance, not being included in joint publications. This was often presented as not being malicious, but simply being forgotten:

A number of the men within this school have put together a book... someone suddenly said to me the other day - "Aren't you upset that you're not in their book?" I realised I'd been writing about that subject for years and nobody had asked me, nobody had thought to ask me if I would like to participate. I just went up to X and said - why wasn't I included in that book, is it because I'm a woman? His response was - oh no, originally it was just me and him and then it grew organically. I said to one of the authors of this book - is it any coincidence that the only woman involved in this book was the one who did the pretty picture on the cover? They got all embarrassed. Gender hasn't really been discussed much here. ....There are always slightly patronising perceptions of younger women. 
Then as women get older, they are seen as maybe support figures, or more recalcitrant people. They get thought of differently, I think there's a way in which perceptions that are never articulated can be really quite damaging. (Sophie, Lecturer)

For one senior woman, leadership was a key issue as it set the norms of inclusivity for the research production process:

I used to not think that leadership mattered in a way, but actually I think it probably does. It's the signals that are given out that people respond to. What's valued and who is encouraged and who is not, etc (Ingrid, Senior Academic).

In sum, the corporatised Shires controlled the research production process in a managerial manner utilising a time/accounting mechanism. This severely constrained the amount of 'official' research time available and individualised its allocation. This had gendered implications because men generally had more time outside of official work hours. Moreover, women tended to engage with nonresearch work in such ways that it was likely to encroach on the research time that they did have available. Finally, there were social factors related to habitus that meant women felt excluded from participation in research processes.

\section{Some conclusions}

Universities in the UK have been increasingly imbricated in the knowledge economy as actors whose role is the production of knowledge. In this paper we have argued that a (perhaps unintended) consequence of this is the development of practices that discriminate against women despite the general awareness and acceptance of gender equity issues at a policy level.

Three elements in the new research economy of universities have been identified: research culture, capital and processes. These are interlinked in that the culture, or habitus of research combines with deployed capital within a research knowledge production process. This paper has demonstrated that, within Shires, management practices reflective of neo-liberal imperatives had come to shape research culture in particular, gendered, ways. Women, consequently, felt excluded. With regards to research capital, women at Shires were prone to capital deficiencies as a consequence of their entry route. Moreover, post-Fordist labour practices meant that the institution did little to equalise staff in this respect. Finally, women were discriminated against in the production process as 
a consequence of the deployment of an industrial-model time/accounting mechanism and factors of homosociability.

Discrimination against women in the new research economy is of some importance because this work constitutes the more prestigious/remunerative aspects of academic work within the contemporary corporatised university. Studies have suggested that the form of new managerialism in British universities varies between institutions and that there are both opportunities and threats for women aspiring to senior positions (Clark, Chandler and Barry 1999). Some authors have asserted that the quantitative transparency of the RAE may allow research active women to claim their right to promotion to senior positions (Morley 2003, Rowbotham 1999).

The institution-specific data in this study leads to less optimistic conclusions. We found that research capital, culture and processes were constructed and operated in such a way as to systematically militate against women's full and equal involvement in research. This institutional discrimination is not, in the main, overtly articulated and may not be malicious. But our research suggests that it is an insidious and inherent part of the research culture in academia. Lack of transparency, increased competition and lower levels of collegiate activity coupled with networking based on homosociability are contributing to a research production process where women are marginalized.

Such institutional sexism poses the dilemma of how it might be tackled. Past, seemingly radical, approaches such as positive discrimination have focused primarily on impediments to women's access rather than providing a comprehensive analysis of the gendered organisations to which access is sought. And whilst some studies (Bowen 1999; Bretherton 2000) suggest that training has a role in attenuating the problems faced by women, there are dangers of such training being presented as the solution to women's position within the academy. Training is often part of a deficit model, where women are encouraged to fit into the status quo rather than challenging aspects of it which are deeply discriminatory.

One of the solutions now suggested at European level is the commitment by organisations to mainstream gender equity. Mainstreaming can be cynically coopted by governments and organizations (Verloo 2004; Walby 2004). But its emergence reflects some acknowledgement of the inadequacies of the strategies intended to promote women's equality by advocating the attainment by women 
of equal status with men on men's terms, rather than an attempt to redefine the terms on which equality may be achieved.

We would argue that concern for gender equity needs to be embedded in processes such as framing of research audit technologies, the management of research work, and research cultures within universities, so that it no longer remains at the level of a parallel discourse. Of course, the likelihood of achieving this within the existing constraints of the present system must be a matter for some scepticism. 


\section{References}

Association of University Teachers (2004) The Unequal Academy : UK academic staff 1995-96 to 2002 to 2003, October 2004, London.

Bagilhole, B. (2002) Against the Odds: Women Academics' Research Opportunities in G. Howie and A.Tauchert (eds) Gender, Teaching and Research in Higher Education, pp. 46-58 Aldershot: Ashgate.

Bett, Sir M. (1999) Independent Review of Higher Education Pay and Conditions, London: Stationery Office.

Becher, T. and Trowler, P. (2001) Academic Tribes and Territories (second edition), Maidenhead: Society for Research into Higher Education and Open University Press.

Boden, R., Cox, D., Neveda, M. and Barker, K. (2004) Scrutinising Science. London: Palgrave.

Boden, R. and Epstein D. (2006) Managing the research imagination: globalisation and research in higher education, Globalisation, Societies and Education 4, 2, 223-36

Bourdieu, P. (1988) Homo Academicus, Stanford: Stanford University Press.

Bowen, L. (1999) Beyond the degree: men and women at the decision-making levels in British Higher Education', Gender and Education 11,1, 5-25.

Bretherton, C. (2001) Gender mainstreaming and EU enlargement: swimming against the tide? Journal of European Public Policy 8,1, 61-81.

Brooks, A., and Mackinnon, A. (eds) (2001) Gender and the Restructured University. Buckingham: Society for Research into Higher Education and Open University Press.

Clark, H., Chandler, J., Barry J (1999) Gender and managerialism in the organisation of UK university life in Fogelberg, P. et al (eds) Hard work in the academy. Helsinki: Helsinki University Press.

Colley, H. (2003) Mentoring for social inclusion: a critical approach to nurturing mentor relationships, London: Routledge Falmer. 
Currie, J., Harris P., Thiele B. (2000) Sacrifices in Greedy Universities: are they gendered? Gender and Education. 12,3,269-291.

Davies, C., and Holloway P. (1995) Troubling transformation: gender regimes and organizational culture in the academy in L. Morley and V. Walsh (eds) Feminist academics: creative agents for change, 7-22, London: Taylor and Francis.

Dean, M. (1999) Governmentality: Power and Rule in Modern Society, London: Sage.

Dearing, Sir R. (1997) The National Committee of Inquiry into Higher Education, London: HMSO

Department of Education and Skills, (2003) White Paper on The Future of Higher Education, 22 January 2003.

Fenton N. (1999) Women - don't buy this line. Guardian Education, p.13, 1 October 1999.

Fenton, N. (2003) Equality will not be achieved without the right resources and laws, Guardian Education, p.13, 1 April 2003.

Forster, N. (2000) A case study of women academics' views on equal opportunities, career prospects and work-family conflicts in a British University, Women in Management Review 15, 7, 316-330.

Giddens, A. (1988) The Third Way, Cambridge: Polity Press.

Halvorsen, E. (2002) Gender Audit, in G. Howie and A. Tauchert (eds) Gender, Teaching and Research in Higher Education : challenges for the twenty-first century, pp9-20, Aldershot: Ashgate.

Harding, S. (2002) The troublesome concept of merit, in G. Howie and A.Tauchert (eds) Gender, Teaching and Research in Higher Education: challenges for the twenty-first century, 248-261. Aldershot: Ashgate.

Harley, S. (2001) Research Selectivity and Female Academics in UK Universities (Economics Working Papers, Occasional Paper 70): Leicester Business School. 
Hatt, S., Kent, J. \& Britton, C. (eds) (1999) Women Research and Careers, London: Macmillan.

HEFCE (2005) Equal Opportunities and Diversity for Staff in Higher Education, available at http://www.hefce.ac.uk/lgm/divers/equal.asp.

Henkel, M. (2000) Academic Identities and Policy Change in Higher Education, London: Jessica Kingsley Publishers.

Horak, R. (2004) Precarious Intellectuals: on the re-structuring of academic life and the précarisation of the 'free researchers' in Austria. Parallax. 10, 2, $90-99$

Howie, G. and Tauchert A. (2002) Gender, Teaching and Research in Higher Education. Burlington, VT, USA: Ashgate.

Husu, L. (2001) Sexism, support and survival in academia, Helsinki: University of Helsinki Press.

Knights, D. and Richards, W. (2003) Sex discrimination in UK academia, Gender, Work and Organization, 10,2,213-38

Lucas, L. (2004) Reclaiming Academic Research Work from Regulation and Relegation in M. Walker and J. Nixon (eds) Reclaiming our Universities from a Runaway World, Maidenhead: SRHE/Open University Press.

Malik, L. and Styver Lie, S. (1994). The gender gap in Higher Education. London: Kogan Page

Morley, L. (2003) Quality and Power in Higher Education. Maidenhead: Society for Research into Higher Education and Open University Press.

National Committee of Inquiry into Higher Education, (1997) Higher Education in the Learning Society, (The Dearing report), London: Stationery Office.

Packer, B. Brown (1995) Irrigating the sacred grove: stages of gender equity development, in L. Morley and V. Walsh (eds) Feminist Academics: Creative Agents for change. 42-56 London: Taylor and Francis.

RAE (2003) Equality Proofing of Research Assessment - Main report, http://www.rae.ac.uk/pubs/other/equproof/. 
Rose, N. (1994) Governing the Soul: The Shaping of the Private Self, London: Routledge.

Rose, N. (1999) Powers of Freedom, Cambridge: Cambridge University Press.

Rowbotham, S. (1999) Locked in the Ivory Tower, Times Higher Education Supplement, 19 February 1999.

Shore, C. and Wright, S. (1999) Audit Culture and Anthropology: Neo-Liberalism in British Higher Education, Journal of the Royal Anthropological Institute, Vol. 5,4, $557-575$

Strathern, M. (2000) Audit Cultures, London: Routledge.

Swain, H . (1998) Fixed Contracts: a female preserve, THES, 3 April 1998.

Swartz, D. (1997) Culture and Power, Chicago: University of Chicago Press.

THES (2003) Times Higher Education Supplement, 21 March 2003.

Tysome, T. (2001) £130 million needed to bridge pay divide. THES, 5 October 2001.

Verloo, M. (2004) Comparing Gender Mainstreaming across Europe: Insights from the MAGEEQ project. Paper presented to ESRC Gender Mainstreaming Seminar Leeds, May 2004.

Walby, S. (2004) Gender mainstreaming: productive tensions in theory and practice. Overview paper presented at ESRC Gender Mainstreaming Seminar series, Leeds, May 2004.

West J \& Lyon K. (1995) The Trouble with Equal Opportunities: the case of women academics, Gender and Education $7,1,51-68$.

Wyn, J., Acker, S., and E. Richards. (2000) Making a Difference: Women in management in Australian and Canadian Faculties of Education, Gender and Education, 12,4, 435-448 
Table 1: Different routes to becoming an academic

\begin{tabular}{|l|l|l|l|}
\hline Entry mode & Teaching activities & Research activities & Professional practice \\
\hline $\begin{array}{l}\text { Researcher Progression more } \\
\text { or less directly } \\
\text { from degrees to } \\
\mathrm{HE} \text { work, } \\
\text { traditional path) }\end{array}$ & $\begin{array}{l}\text { May have limited experience } \\
\text { and opportunity. }\end{array}$ & $\begin{array}{l}\text { Assumed to have good skills } \\
\text { and awareness. May progress } \\
\text { through fixed term research } \\
\text { contracts. }\end{array}$ & $\begin{array}{l}\text { Will vary according } \\
\text { discipline. }\end{array}$ \\
\hline $\begin{array}{l}\text { Professional } \\
\text { Previously } \\
\text { worked as a } \\
\text { professional } \\
\text { practitioner of } \\
\text { some sort) }\end{array}$ & $\begin{array}{l}\text { Often employed for more } \\
\text { vocational teaching work (eg. } \\
\text { law, social work) therefore } \\
\text { presumed to have necessary } \\
\text { technical knowledge for such } \\
\text { teaching. }\end{array}$ & $\begin{array}{l}\text { May or may not be from } \\
\text { professional culture which } \\
\text { engages with research, giving } \\
\text { some opportunity to develop } \\
\text { necessary skills. }\end{array}$ & $\begin{array}{l}\text { Assumed to be competent in } \\
\text { this area. }\end{array}$ \\
\hline $\begin{array}{l}\text { Teacher } \\
\text { Entered } \\
\text { primarily to teach, } \\
\text { variety } \\
\text { backgrounds) }\end{array}$ & Assumed to be competent. & $\begin{array}{l}\text { Probably minimal previous } \\
\text { engagement with research, } \\
\text { limited research awareness and } \\
\text { skills. }\end{array}$ & $\begin{array}{l}\text { May well have only minimal } \\
\text { relevant } \\
\text { experience. }\end{array}$ \\
\hline
\end{tabular}

